\title{
PERCEPÇÃO E RISCOS, ABORDAGEM SOCIOAMBIENTAL DO PROCESSO SAÚDE-DOENÇA
}

\author{
perception and risk, an socioenvironmental approach of process health-disease \\ Natacha Cíntia Regina Aleixo* \\ João Lima Sant’Anna Neto**
}

\begin{abstract}
Resumo
A sociedade atual cria riscos que afetam de forma desigual à população. Na área urbana de Ribeirão Preto, durante o período do verão e início do outono, ocorrem surtos epidemiológicos de doenças de veiculação hídrica, principalmente, a dengue e a leptospirose. A manifestacão dessas doenças acontece em diferentes áreas de risco. O objetivo desta pesquisa foi avaliar a percepção da população em relação às doenças de veiculação hídrica em Ribeirão Preto. Os dados da incidência das doenças de veiculação hídrica foram analisados estatisticamente e mapeados com o software Mapinfo 9.0. A partir disso, trezentas pessoas residentes nas áreas de maior incidência responderam a um questionário para estudos de identificação da relação ambiente-saúde, da valorização das experiências vividas, dos mecanismos cognitivos e da satisfação humana com suas condutas resultantes. As avaliações mostraram que a maior parte dos citadinos acredita que a reincidência dessas patologias se deve a população que não coloca em prática as medidas de prevencão. Isso gera os mais variados sentimentos nas pessoas, principalmente a preocupação, o medo e a raiva, que induzem a uma postura individualista e frustrada, ao invés de proporcionar a troca de informações no convívio social e motivar a conduta preventiva na população.
\end{abstract}

Palavras-chave: Percepção dos riscos, saúde, doenças de veiculação hídrica.

\begin{abstract}
Modern society creates risks that affect the population unequally. In the urban area of Ribeirão Preto, during the summer and early autumn, epidemiological outbreaks of waterborne diseases have occurs, mainly dengue and leptospirosis. The manifestation of these diseases occurs in different areas of risk. The purpose of this study was to evaluate the perception of the population in relation to waterborne diseases in Ribeirao Preto. The waterborne disease incidence data were statistically analyzed and mapped with the software Mapinfo 9.0. From this, three hundred people living in the most affected areas answered a questionnaire to identify the environmental-health relation, the appreciation of life experiences, and the cognitive mechanisms of human satisfaction with their resulting behavior. The evaluations showed that most of the townspeople believe that the recurrence of these diseases is due to the population that does not put in place preventive measures. It has generated mixed feelings in this people, especially the worry, the fear and the anger, which can lead to an individualistic stance and frustration, instead of providing the exchange of information in social life and motivate a preventive behavior in the population.
\end{abstract}

Key words: Perceived risk, health, waterborne diseases.

\begin{abstract}
Resumen
La sociedad moderna crea riesgos que afectan a la población de forma desigual. En el área urbana de Ribeirão Preto, durante el otoño y princípios de verano, se producen brotes epidemiológicos de enfermidades transmitidas por el água, en especial el dengue y la leptospirosis. La manifestación de estas enfermedades se produce en diferentes áreas de riesgo. El objetivo de esta investigación es conocer la percepción que tiene la población acerca de las enfermedades transmitidas por el agua en Ribeirão Preto. Para ello, los datos de incidencia de enfermedades transmitidas por el agua fueron estadísticamente analizados y cartografiados mediante el software Mapinfo 9.0. A partir de esto, 300 personas respondieron a un cuestionario que tuvo por objetivo identificar la relación entre el medio ambiente y la salud, la valoricación de las experiencias de vida, los mecanismos cognitivos y la satisfacción humana con sus conductas resultantes. Los resultados mostraron que la mayoría de encuestado cree que la reincidencia de esas patologias se debe a que existe población que no pone en práctica medidas preventivas. Esto genera una gran variedad de sentimientos en las personas, sobre todo preocupación, miedo e ira, que inducen a una postura individualista y frustada, en lugar de facilitar el intercambio de información en convivencia social y motivar conductas preventivas en la población.
\end{abstract}

Palabras clave: Percepción de riesgo, salud, enfermedades transmitidas por el agua.

(*) Doutoranda do Programa de Pós-graduação em Geografia da Universidade Estadual de São Paulo - Rua Roberto Simonsen, 305 - CEP: 19.060-900 Presidente Prudente (SP) - Brasil, Tel.: (+ 55 18) 3229.5417 - natachaaleixo@yahoo.com.br

(**) Prof. Dr.do Programa de Pós-graduação em Geografia da Universidade Estadual de São Paulo - Rua Roberto Simonsen, 305 - CEP: 19.060-900 Presidente Prudente (SP) - Brasil, Tel.: (+55 18) 3229.5417 - joaolima@fct.unesp.br 


\section{INTRODUÇÃO}

Com a intensificação do processo de urbanização, as ações antrópicas no ambiente tornaram-se mais complexas, com a expansão territorial urbana e a produção do espaço de forma desordenada. Com isso, o que caracteriza as cidades contemporâneas, é justamente a profunda desigualdade social na exposição aos riscos ambientais.

$\mathrm{Na}$ Modernidade, sobretudo no mundo Ocidental, o risco é criado socialmente e ligado ao conceito de perigo, quer os sujeitos estejam ou não conscientes dele. Os perigos são codificados como "riscos", na medida em que os sujeitos podem exercer controle sobre eles. Assim, o risco não é novo, o novo é que a sociedade passa a gerá-lo e a naturalizar a convivência com ele e suas consequências. Daí a denominação dada por Beck (1992), de sociedade de riscos. (ZANIRATO et al, 2008; CIAMB, 2009).

A sociedade atual se distingue por criar riscos, muitos dos quais afetam de modo desigual a população. A gestão de riscos é uma das preocupações de governos e agências internacionais desde o século XX. Porém, nem sempre as ações se orientam sobre uma matriz reflexiva, que aponte as diferentes interpretações sobre o risco. (ZANIRATO et al, 2008).

Conforme a Organização Mundial da Saúde (OMS), não se pode eliminar o risco por completo, pois não existe risco zero. Os indivíduos e os lugares percebem as ameaças de diferentes formas, de acordo com suas práticas culturais e sociais. Neste contexto, a saúde e o meio ambiente não podem ser desvinculados, pois, os riscos se materializam no ambiente e podem afetar a todos de diferentes maneiras.

Entende-se a percepção como um processo mental, de interação do individuo com o meio ambiente, que se dá através de mecanismos perceptivos propriamente ditos e, principalmente cognitivos. Os primeiros são dirigidos pelos estímulos externos, captados por meio dos sentidos, onde a visão é a que mais se destaca. O segundo são aqueles que compreendem a contribuição da inteligência, uma vez admitindo-se que a mente não funciona apenas a partir dos sentidos e nem recebe essas sensações passivamente, existem contribuições ativas do sujeito ao processo perceptivo desde a motivação, a decisão e a conduta. (DEL RIO e OLIVEIRA, 1996).

A enfermidade não só modifica concretamente sua expressão epidemiológica e clínica como também passa a ser percebida e enfrentada de forma diversa pela sociedade. A representação, o significado e a subjetividade que circundam as velhas epidemias do mundo pós-moderno se diferenciam "dos tempos do cólera". (CARVALHEIRO apud DONALÍSIO 1999, p. 27).

A maioria das doenças hídricas estão epidemiologicamente controladas, no entanto, há uma discussão em voga na comunidade acadêmica sobre a ocorrência dessas doenças em caráter de emergência ou reemergência, uma vez que ambas estão associadas e são potencializadas principalmente pelos processos de impacto e degradação socioambiental, bem como pelos padrões cotidianos da vida atual, ligados aos tempos rápidos, de alta competitividade e de forte interesse econômico.

Ressalta-se que essas doenças são demonstrações de alerta a problemas de nossa época que depois de eliminados, posteriores surgirão, pois segundo Confalonieri (2002), "idealizar uma sociedade desenvolvida 'saneada' a ponto de se ver livre do risco de emergência - ressurgência dos processos infecciosos é praticar a irrealidade.

Por isso, a partir das reemergências dessas patologias o que está em análise são as falhas nas práticas de saúde dos sistemas de saúde, pois, a consolidação das ações propostas, ainda perpassa a dificuldade de incorporar na visão dos profissionais e da população o tripé saneamento-saúde-ambiente.

De acordo com a World Health Organization (2003, p. 3), apenas a percepção da severidade dos riscos inerentes às doenças de veiculação hídrica é que seria capaz de dimensionar a significância da emergência de determinadas doenças infecciosas mostrando que na realidade existe uma alocação imprópria de recursos. Isto confirma a necessidade de maiores investimentos na criação de infra-estruturas dos serviços de saúde aptas a atender a demanda apresentada. 
No ano de 1998, o Banco de dados do Sistema Único de Saúde (DATASUS), ao avaliar as causas das internações, o grupo de causa das doenças infecciosas e parasitárias, onde predominam as doenças veiculadas pela água, registrou um total de 908.900 internações, sendo inferior apenas às internações referentes à gravidez, parto e puerpério e às enfermidades do aparelho respiratório e circulatório.

Esse grupo de causa foi responsável por $4,9 \%$ do valor total dos gastos pagos em hospitalizações pelo Sistema Único de Saúde (SUS), sendo a faixa etária mais atingida de zero a cinco anos de idade (20,44\% dos atendimentos hospitalares). (BRASIL, 2001).

No decorrer dos anos, o total de casos de doenças de veiculação hídrica apresentou diminuição em todo país, pelos programas de saneamento e políticas de educação em saúde. Atualmente, ocorre o aumento do grupo das doenças crônico-degenerativas e respiratórias, no entanto, a relação das condições desiguais de saneamento ambiental e de informação à saúde em diferentes partes do país, ainda expõe a população as patologias de veiculação hídrica.

Como em grande parte das áreas urbanas do Estado de São Paulo, na cidade de Ribeirão Preto, localizada na região nordeste deste estado, ocorrem episódios de enchentes e inundações durante o período da primavera/verão.

A cidade teve seu primeiro curso d'água canalizado e retificado a partir de 1884, primeiramente essa obra foi realizada para melhorar o saneamento da cidade e tentar mitigar os problemas de saúde pública que ocorriam durante o verão, quando os córregos transbordavam inundando suas várzeas e favorecendo a proliferação de mosquitos transmissores das chamadas febres palustres, além de moléstias como a febre amarela. (MAIA, 2007, p. 30)

Uma das consequências das enchentes e inundações são os problemas de saúde pública, pela deterioração da qualidade da água e o contato da população no período das cheias.

Essas condições potencializam a veiculação de doenças hídricas, principalmente à população exposta a riscos de inundações. Lembrando, que uma área é caracterizada como de risco tanto pela fragilidade do ambiente quanto pela vulnerabilidade socioeconômica.

Na cidade de Ribeirão Preto são elevados os riscos associados à produção do espaço urbano e a incidência das doenças de veiculação hídrica, principalmente da Dengue e da Leptospirose, que apresentaram a maior incidência nos últimos dez anos dentre as todas as doenças de veiculação hídrica na área intra-urbana.

A dengue é uma doença infecciosa aguda de curta duração, de gravidade variável, causada por um vírus e transmitida pelo mosquito Aedes aegypti infectado. O agente causador é um arbovírus do gênero Flavivírus, pertencente à família Flaviviridae, sendo conhecidos quatro sorotipos: 1, 2, 3 e 4. É transmitida por um vetor, sendo que Aedes aegypti é o principal vetor de dengue no mundo. Entre outros vetores de menor importância epidemiológica estaria o Aedes albopictus, vetor de manutenção da doença na Ásia, porém ainda não foi registrada transmissão de dengue por este no continente Americano. (SUCEN, 2002).

O estudo de Pontes (1992) e Pontes e Rufino Neto (1994) analisou a primeira epidemia ocorrida em Ribeirão Preto no ano de 1990/1991 e destacou que a progressão geográfica da infestação pelo Aedes aegypti ocorreu na direção dos municípios situados no oeste para aqueles do leste no estado de São Paulo. Em 1986 foi detectada a presença também do Aedes albopictus no Estado de São Paulo, no Vale do Paraíba, provavelmente originário do Rio de Janeiro, posteriormente, no Município de Ribeirão Preto e municípios da Região de Campinas. Este vetor caminhou na direção de leste para oeste. Dentro da área intra-urbana em 1990, 50\% dos casos foram provenientes de quatro bairros: Ipiranga, Vila Albertina, Vila Virgínia e Campos Elíseos.

Todavia, para Koury e Silva (2006), "a Leptospirose é considerada uma doença infecciosa emergente e endêmica, transmitida na maioria das vezes pela urina de roedores, que são os principais 
reservatórios da bactéria Leptospira. Os ratos (Rattus novergicus, Rathus ratus e musmusculares), são portadores assintomáticos universais. A população adquire essa patologia ao entrar em contato com a urina destes animais".

Apesar da Leptospirose não proporcionar surtos epidêmicos na cidade, é também transmitida durante o período do verão e relacionada principalmente às áreas urbanas, em especial aquelas cujo crescimento desordenado somado às áreas de segregação sócio-econômica, viabiliza o contato com as águas provenientes das inundações urbanas, lixos espalhados por vias e terrenos baldios, que propiciam o ambiente ideal para transmissão da leptospirose.

Neste contexto, o objetivo deste artigo é analisar a percepção das doenças de veiculação hídrica nas principais áreas de incidência no espaço urbano de Ribeirão Preto.

\section{A PERCEPÇÃO DOS RISCOS NA SAÚDE HUMANA}

O risco foi um conceito utilizado desde o período das grandes navegações ligado as transações comerciais, e ao lucro visando à perda ou ganho, em um viés característico da economia. No período atual o risco associa-se ao perigo. . (LIEBER e LIEBER, 2002; CASTIEL, 2002).

Para Spink (2001) ocorre uma incorporação gradativa de termos, passando da fatalidade a fortuna primeiramente, e incorporando vocábulos como hazard (século XII), perigo (século XIII), sorte e chance (século XV) e risco no século XVI. (LIEBER e LIEBER, 2002; GONDIM, 2007).

O próprio termo risco existe em diferentes idiomas e possui significados distintos, por isso, ocorre muitas vezes à contradição no sentido e significado atribuído ao risco e perigo, além do significado deles às diferentes ciências que estudam o risco também ser contundente, ora utilizado como forma de se relacionar com o futuro, ora como aventura na qual a imprevisibilidade é parte do jogo, ou ainda como estratégia de controle e dominação. (HOGAN; MARANDOLA, 2004; SPINK, 2001; GODIM, 2007; VEYRET, 2007)

$\mathrm{Na}$ ciência Geográfica, o entendimento da relação sociedade-natureza é multicêntrico, e o aparecimento do conceito de risco ocorre primeiramente nos estudos dos naturais hazards, desde a década de 1920, de acordo com a revisão de literatura realizada por Hogan e Marandola (2004, 2005) esta tradição surge, portanto, muito antes dos apelos mundiais pela degradação ambiental planetária, ou mesmo antes dos apelos mais recentes ao resgate da qualidade de vida urbana, inicia-se com Ian Burton (1927), a partir de pesquisas de caráter intervencionista, que propunham medidas para solucionar o problema das inundações, financiadas pelo governo norte-americano. No entanto, a maioria dos estudos estava ligada a ação antrópica sobre o ambiente, e eram realizados pelos geógrafos "físicos".

Risco (risk) é utilizado pelos geógrafos como uma situação, que está no futuro e que traz a incerteza e a insegurança. Assim, há regiões de risco (regions of risk) ou regiões em risco (regions at risk). O que é estar em risco? É estar suscetível à ocorrência de um hazard. (HOGAN e MARANDOLA, 2004, p.6)

Essa linha de investigação, ainda foi utilizada na era sanitarista-higienista no âmbito da saúde pública e planejamento das cidades, em que as ações mitigadoras se baseavam em medidas estruturais de engenharia, para contenção das inundações e extermínio das doenças infecciosas de veiculação hídrica, que ainda hoje são propostas por muitos interventores públicos e vistas na maioria das cidades brasileiras.

A Organização das Nações Unidas, por exemplo, ainda utiliza a concepção do risco relacionada aos desastres naturais, e recentemente divulgou o relatório realizado em parceria com a the United Nations International Strategy for Disaster Reduction (UNISDR), de mitigação dos riscos pelo mundo, associados aos eventos climáticos e geológicos extremos. Assim, o hazard é definido como:

.... a potentially damaging physical event, phenomenon or human activity that may cause the loss of life or injury, property damage, social and economic disruption or environmental degradation" each hazard 
being characterized by its location, intensity, frequency and probability. It then defines vulnerability as "the conditions determined by physical, social, economic, and environmental factors or processes, which increase the susceptibility of a community to the impact of hazards. (MORJANI et al, 2007, p.3)

Contextualizando o risco ligado aos fenômenos físicos, ele foi progressivamente alavancado pelo desenvolvimento da teoria da probabilidade, que muitas vezes desconsidera aspectos do fenômeno estudado, como uma modelagem matemática que busca respostas desejadas desejadas (LIEBER e LIEBER, 2002). Inúmeros exemplos podem ser vistos nos estudos epidemiológicos, quando se utiliza o estimador de risco relativo (RR), se quer representar a proporção de pessoas expostas a um fator de risco, que desenvolveram a doença, sobre a proporção de não expostas que também desenvolveram a doença (GODIM, 2007). No entanto, apenas o risco relativo não é suficiente para compreender o processo saúde-doença na sua multidimensionalidade, uma vez que este é influenciado por fatores que ultrapassam a mensuração, ou mesmo são impossíveis de serem mensurados, como a subjetividade, por exemplo.

Neste sentido, Rouquaryol (1994), afirmou que na análise epidemiológica, às variáveis independentes são consideradas fatores de risco se puderem ser associadas às doenças, contanto que estas associações sejam julgadas válidas, a luz dos critérios epidemiológicos. A associação de fatores condicionantes da doença, não é um simples resultado de justaposição, mas uma relação sinérgica, dois fatores estruturais aumentam o risco da doença, mas do que faria uma simples soma. A mesma autora, explicou que quando não mais existirem dúvidas da contribuição da variável na causação, dito fator será reconhecido como fator de risco.

$\mathrm{Na}$ década de 80 , outros pesquisadores relacionaram o principal produto dos hazards, o risco, à diferentes vulnerabilidades, que variam conforme a organização social produzida, principalmente, nos estudos voltados a sociedade do risco, advindos da sociologia, da análise dos sistemas ambientais e dos estudos da percepção do risco ligados à fenomenologia.

No tratamento da sociedade de risco, a crítica dos autores é referente à crença imensurável de que a solução para os problemas atuais, deve se basear na tecnologia e no conhecimento científico.

Conviver com a iminência do risco e expor-se ao mesmo é um risco que essa sociedade tem que correr por conta do seu desenvolvimento técnico-industrial e econômico que antes era visto como solução e agora é observado como problema problema (WOLFGANG, 2009). A sociedade do risco é uma sociedade catastrófica. Nela, o estado de exceção se torna o estado de normalidade. (BECK, 1992)

Hogan e Marandola (2004) contextualizam a contribuição dos geógrafos no questionamento dos riscos que ainda não possuem operacionalização por partes dos gestores públicos.

Além da questão óbvia colocada (que as populações são afligidas pelo risco e pelo perigo ambientais), os geógrafos contribuíram muito ao formular uma questão anterior: como é percebido o perigo pelas populações afetadas? Têm as populações percepção da natureza do risco que correm? Esta é, sem dúvida, uma questão central que ainda continua passando despercebida ou não operacionalizada pelos órgãos gestores do território de todos os âmbitos, nem completamente colocada em relevo pela academia. $\mathrm{O}$ que ocorre em consequência é a delimitação de intervenções sem considerar como de fato as populações concebem a sua situação. (HOGAN e MARANDOLA, 2004, p.11)

O risco deriva da conjugação de fatores, sociais, biológicos, econômicos, demográficos, naturais, a atuar em sistema complexo e exigir interpretação e adoção de diferentes perspectivas da dimensão espacial: os planos geométrico, espacial, territorial e do lugar (BARCELLOS, 2000). Neste último, resultam as ações e os processos espaciais, relacionados à vivência e aos sentidos atribuídos ou reinventados pelos indivíduos, como as paisagens medo, a topofobia, a topofilia, a angústia ou sucesso, de acordo com o contexto vivido. (NOSSA 2008; DEL RIO; OLIVEIRA, 1996).

Por isso, neste artigo, a abordagem da corrente de análise da percepção do risco é necessária, para verificar a relação de "vivência no lugar e apreciar os laços afetivos que se estabelecem com o 
espaço" (NOSSA, 2008 ). Compreende-se que uma análise socioambiental necessita da utilização de diferentes categorias da geografia bem como de métodos de outras ciências, para o equacionamento e solução do problema pesquisado. (MENDONÇA, 2002).

O reconhecimento e aprofundamento das relações de multicausalidade, na investigação dos quadros de saúde e de doença, impõem a Geografia a manutenção de uma dialética produtiva e inovadora com as demais ciências, incorporando novas e diversas tendências interpretativas cujas implicações começam a ser observáveis ao nível das práticas médicas, das políticas de saúde e da compreensão e valorização social do fenômeno da doença, reclamando uma abordagem humanista e integradora. (NOSSA, 2008)

Nessa abordagem o espaço passa a ser observado, de acordo com a figura 1, como agente ativo na modelação da experiência em saúde, passando da referencia locativa à compreensão do lugar e da paisagem, como centros de atividade social, valorizando o nexo de partilha e de simbologia pessoal (RELPH, 1987 apud NOSSA, 2008).
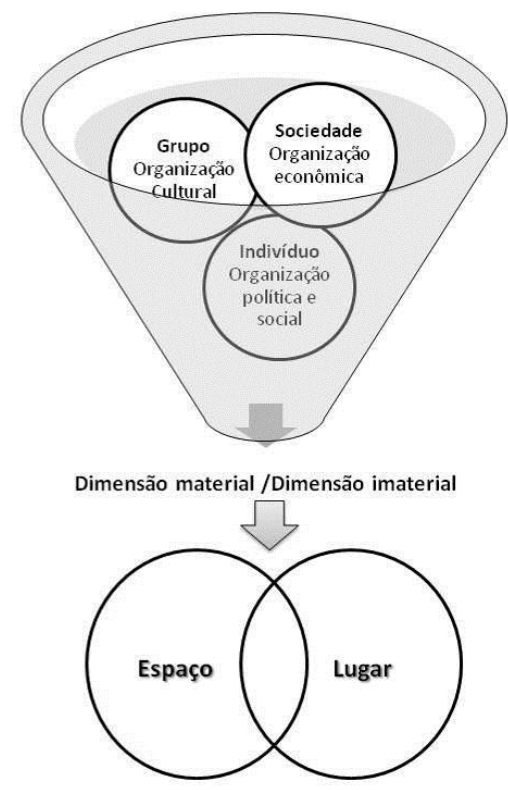

Figura 1 - Quadro de Referência contemporânea da construção multidimensional do espaço.

Fonte: NOSSA (2008), modificado e adaptado por ALEIXO (2009).

Para Tuan (1983), na escala individual, o espaço é uma dimensão extensa e abstrata (o planeta, o universo), intangível de ser conhecido integralmente por meio da experiência e dos sentidos. Entretanto, o lugar são aquelas porções (fragmentos geralmente conectados) desse espaço, que nos remete a uma memória, a uma vivência: o bairro onde moramos, a casa, o lugar de trabalho, os lugares de lazer, o lugar de pausa. Estes, para nós, possuem uma localidade no vasto mundo, possuem cores, cheiros e paisagens que nos envolvem e trazem, portanto, nosso júri de valores sobre eles: agradável, caótico, violento ou pacato. (DE PAULA e MARANDOLA JR, 2009).

"A percepção é a apreensão de uma qualidade sensível, acrescida de uma significação, como uma qualidade essencial e não apenas um acréscimo, está intimamente ligada e subordinada às condições limitativas da proximidade no espaço tempo". (OLIVEIRA, 2002)

Por isso, ao lado dos estudos econômicos, sociais e tecnológicos e políticos, o estudo da percepção ambiental é exigido pela própria complexidade dos sistemas de representação do fenômeno urbano, que se apresenta como interdisciplinar na sua essência. Não se pulveriza o objeto com abordagens provindas de diversas óticas do conhecimento, mas procura-se cercá-lo e compreendê-lo na sua complexidade para planejar e intervir em sua dinâmica. (DEL RIO e OLIVEIRA, 1999) 


\section{PROCEDIMENTOS METODOLÓGICOS}

Os dados dos casos notificados e confirmados da Leptospirose e Dengue, por endereço, do período de 1998 a 2008, foram coletados da Prefeitura Municipal de Ribeirão Preto/SP.

Depois desta etapa, os casos foram georreferenciados, para isso, utilizaram-se as bases por endereço urbano e setor censitário de Ribeirão Preto, fornecidas pelo Instituto Brasileiro de Geografia e Estatística (IBGE) e pela Prefeitura Municipal de Ribeirão Preto-SP.

Inicialmente, procedeu-se com a forma automática de geocodificação, recorrendo posteriormente, a geocodificação interativa. Assim, foram diagnosticados os padrões de pontos dos casos de dengue e leptospirose.

O mapeamento dos casos foi feito no software MapInfo 9.0. Alguns endereços tiveram problemas e não foram passíveis de geocodificação, pois, estavam incompletos, se tratavam de ruas novas, e não possuíam numeração das residências.

Do total de 10 anos, pode-se identificar a localização dos casos de dengue por endereço em 14.811, ou seja, percentualmente $97,9 \%$ dos casos, conforme a tabela 1 .

A localização dos casos de leptospirose por endereço foi de $100 \%$.

Tabela 1. Casos de dengue geocodificados entre 1998 e 2008

\begin{tabular}{l|c|c|c|c}
\hline \multirow{2}{*}{ ANOS } & \multicolumn{2}{|c|}{ GEOCODIFICADOS } & \multicolumn{2}{c}{ NÃO GEOCODIFICADOS } \\
\cline { 2 - 5 } & absoluto & relativo & absoluto & relativo \\
\hline $1998-1999$ & 294 & 94,9 & 16 & 8,6 \\
\hline $1999-2000$ & 233 & 99,5 & 1 & 0,5 \\
\hline $2000-2001$ & 2.572 & 95,5 & 121 & 4,5 \\
\hline $2001-2002$ & 737 & 95,9 & 31 & 3,9 \\
\hline $2002-2003$ & 754 & 97,6 & 18 & 2,4 \\
\hline $2003-2004$ & 161 & 96,4 & 6 & 3,6 \\
\hline $2004-2005$ & 443 & 93,8 & 29 & 6,2 \\
\hline $2005-2006$ & 4.917 & 99 & 46 & 1 \\
\hline $2006-2007$ & 3.406 & 99,3 & 23 & 7 \\
\hline $2007-2008$ & 1.294 & 99 & 13 & 1 \\
\hline
\end{tabular}

Fonte: Software Mapinfo 9.0.Org.anizado por: ALEIXO, 2009

Depois disso, inseriu-se a malha por setor censitário do IBGE para avaliar quais os setores de maior incidência das respectivas patologias.

Os dados dos casos de dengue e leptospirose por endereço foram agrupados por setor censitário, utilizando-se do coeficiente de incidência epidemiológica, calculado de acordo com a seguinte fórmula explicitada por Rouquayrol, 1994:

C. I. $=$

Número de casos novos x 10n

\section{População}

Em que n, determina o tamanho da amostra da população. Nesta pesquisa, o valor de $n$ é igual a 4, e portanto, os coeficientes de incidências da patologia, foram expressos por 10.000 habitantes para cada setor censitário da cidade.

A partir disso, a análise da categoria geográfica lugar, torna-se para esta pesquisa, uma ponte entre o espaço e o indivíduo, as políticas públicas e as ações efetuadas, os diferentes signos e sensações envolvidas no processo saúde-doença, tudo isso levando em conta a dimensão do cotidiano da população. Uma vez que dada situação não pode ser plenamente aprendida se, a pretexto de con- 
templarmos sua objetividade deixamos de considerar as relações intersubjetivas que a caracterizam.

Para isso, foram realizadas de forma preliminar 6 entrevistas, nas áreas de risco de incidência de dengue e leptospirose, durante o período do mês de outubro de 2009, utilizando-se de aparelho gravador.

Segundo Silvermann (1997), a entrevista qualitativa é uma conversa direcionada, que o entrevistador tem pretensão de obter as perspectivas, experiências e sentimentos dos participantes da pesquisa.

Como critérios de inclusão selecionaram-se moradores das áreas de incidência das doenças de veiculação hídrica na cidade de Ribeirão Preto. Os sujeitos de análise do projeto correspondem a toda a população residente nas respectivas áreas da cidade de Ribeirão Preto, independente do gênero, profissão ou cor, com idade superior a 18 anos.

As entrevistas foram semi-estruturadas e compostas por cinco perguntas norteadoras:

. Gostaria que você me dissesse um pouco do tempo em que você vive aqui no bairro.

. O que você pensa sobre a relação entre a água e a transmissão de doenças?

- Em que época do ano você acha que ocorre doenças como a leptospirose e a dengue? Por quê?

. O que você faz para se prevenir dessas doenças?

- O que acha que poderia ser feito para tornar seu bairro mais saudável?

Posteriormente a realização de cada entrevista, foi feita a transcrição com a preservação da identidade dos entrevistados através de nomes fictícios. As entrevistas foram transcritas literalmente, $100 \%$ das falas.

A análise dos dados das entrevistas seguiu as três fases propostas por Bardin (2002, p. 153220), que primeiramente é a pré-análise em que as entrevistas transcritas são organizadas, a segunda fase de descrição analítica dos discursos, em que são utilizados procedimentos de classificação, codificação, que visam à busca de sínteses coincidentes e divergentes de idéias. Na terceira fase de interpretação inferencial, a reflexão e a intuição possibilitam o estabelecimento de relações, revelando o conteúdo latente dos discursos.

Adotou-se o procedimento de codificação, que foi realizado de forma manual, e posteriormente foram sumarizadas as categorias em tabelas.

As categorias inicialmente pertinentes a análise de dados foram: satisfação humana, sentimentos, aceitabilidade, valores e conhecimentos.

De posse da análise dos dados das entrevistas em profundidade, foi desenvolvido um modelo de questionário aplicável as áreas de incidência das doenças de veiculação hídrica, composto por questões fechadas, que enfatizaram o conhecimento, a conduta resultante, a satisfação, e os sentimentos que permeiam a percepção dos citadinos, com relação aos fatores de risco e incidência das doenças: dengue e leptospirose no seu local de vivência.

Nessas respectivas áreas de risco, delimitadas por setor censitário, foram selecionados para realização dos questionários, apenas os setores que apresentaram os maiores coeficientes de incidência de dengue e leptospirose nos dez anos analisados, conforme a Figura 2.

Foram selecionadas seis áreas da cidade, em cada uma 50 questionários foram aplicados, no total 300 pessoas responderam os questionários. No percurso pelas áreas, foi utilizado o procedimento de amostra convencional, as pessoas tiveram o livre consentimento para responderam as questões e optar pela participação na pesquisa. Esclarecidas as condições de preservação da identidade e da destinação dos resultados, as pessoas decidiam a participação. 


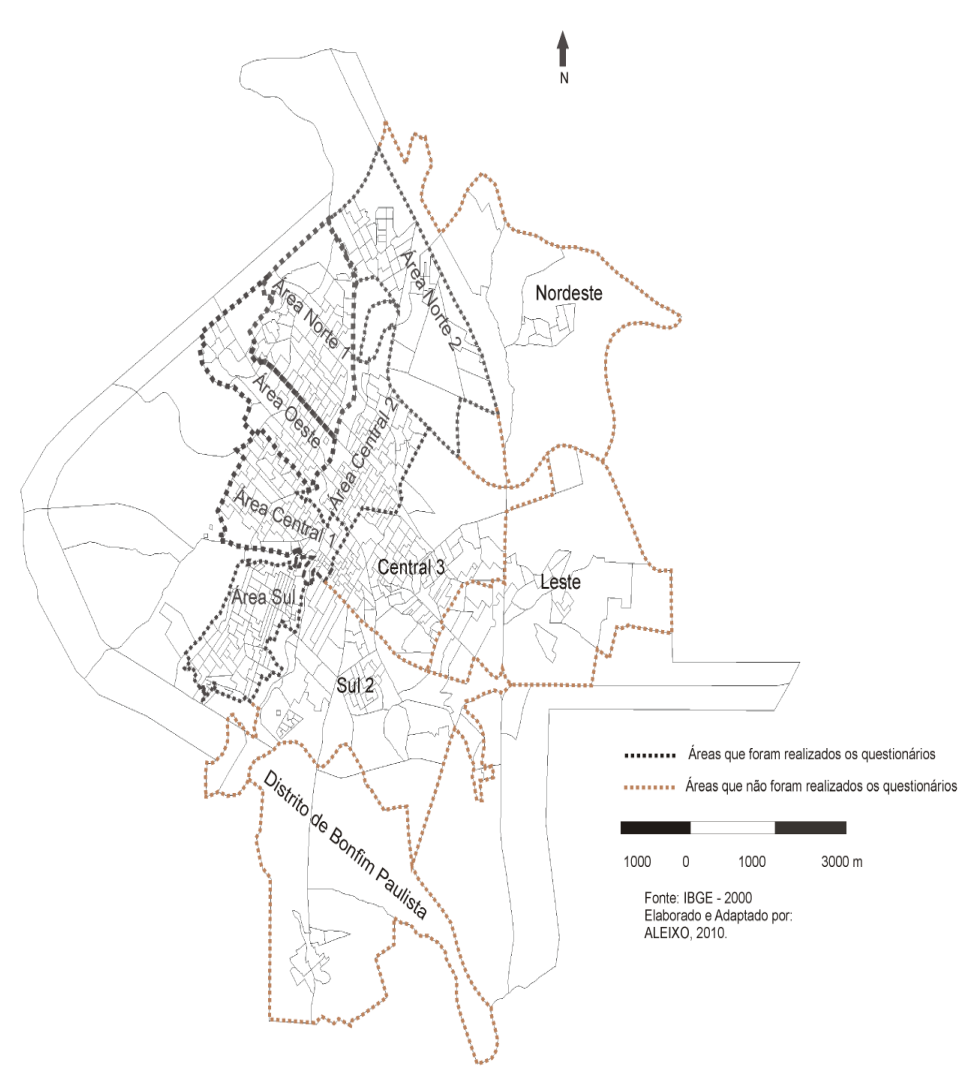

Figura 2 - Áreas selecionadas para realização dos questionários. Organizado por: ALEIXO, 2010.

Além disso, foram realizados trabalhos de campo no período de setembro a dezembro de 2009, utilizando-se do recurso fotográfico para evidenciar possíveis fatores de risco associados a incidência das respectivas patologias.

\section{RESULTADOS E DISCUSSÕES}

A maioria dos questionários foram respondidos por pessoas com idade acima de 60 anos e entre 50 e 60 anos, predominantemente, do sexo feminino, conforme as figuras 3 e 4.

O grau de escolaridade das pessoas que responderam os questionários foi importante para avaliar o conhecimento sobre as patologias de veiculação hídrica, e auxiliar o entendimento do comportamento de risco. Nas áreas Sul e Oeste, a maioria dos questionários foram respondidos por pessoas que possuíam apenas o ensino fundamental. Nas áreas Norte 2, Norte 1, Central 2 e Central 1, a maioria dos entrevistados possuíam o ensino médio completo. Os questionários respondidos por parte dos entrevistados que possuíam ensino superior completo, foi predominante nas áreas Central 1 e Sul, conforme observa-se na figura 5.

O total de entrevistados que se declarou analfabeto, foi maior na área Norte 2. Nas áreas Central 1 e Sul, não ocorreu essa resposta.

Com relação ao tempo de residência no local, observa-se na figura 6, o predomínio nas áreas Sul, Oeste e Central 1, de moradores que residem no bairro ou proximidades a mais de 30 anos. Essas áreas são antigas e surgiram com o início da formação da cidade, em que os bairros localizavam-se próximos a área do centro comercial e da confluência dos córregos Retiro Saudosos e Ribeirão Preto. 


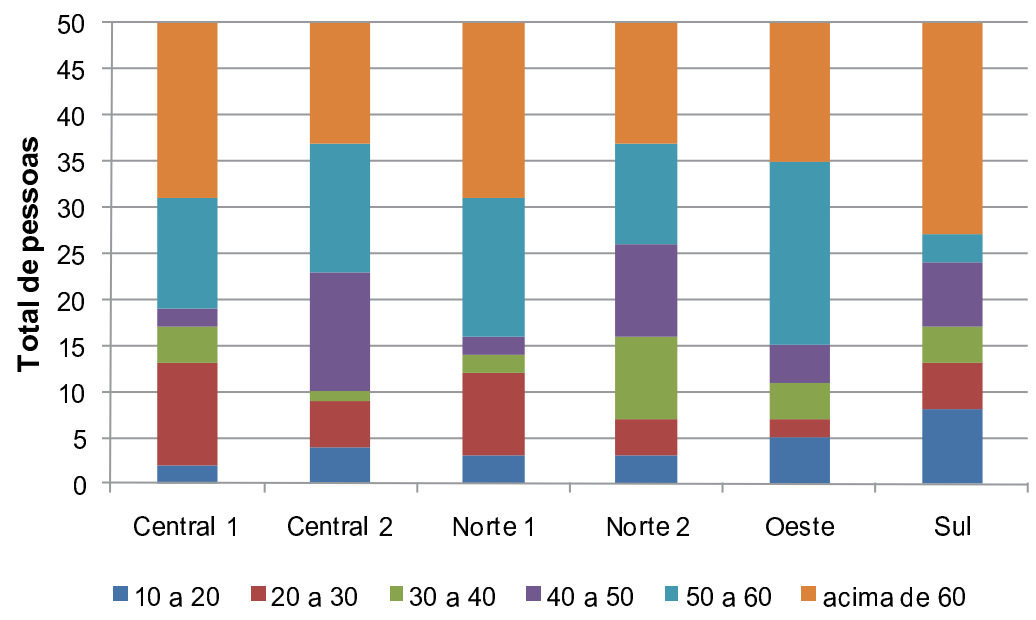

Figura 3- Gráfico dos Questionários respondidos por faixa etária

O tempo de residência é uma variável importante, pois, o indivíduo possui a memória dos acontecimentos que ocorreram naquele lugar, mas, não deve ser confundido como uma condição para estarem menos expostos ao risco, pois, muitos hábitos desenvolvidos no cuidado do lar, são de difícil mudança.

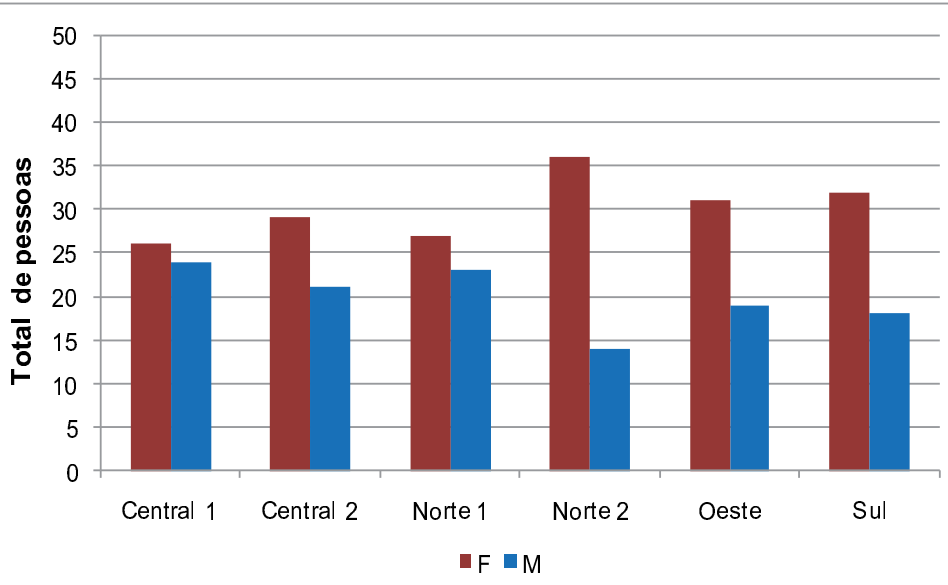

Figura 4 - Gráfico dos Questionários respondidos por sexo

Muitos dos criadouros domésticos provêm dos vasos de plantas, que os moradores insistem em deixar o recipiente com água em baixo, principalmente a população idosa, conforme mencionado pelos funcionários da secretaria de saúde de Ribeirão Preto. Por isso, a mudança de hábito para prevenção do risco epidemiológico, nestas áreas, pode ser uma tarefa árdua.

Nas áreas Norte 1 e Norte 2, a maioria dos questionários foram respondidos por moradores que residiam de 20 a 30 anos e de 10 a 20 anos nas áreas, em grande parte dos bairros não houve mudança significativa do padrão construtivo, alguns ainda possuem favelas, entretanto, em parte pequena dos bairros, as casas foram reformadas, atingindo padrão construtivo elevado. 


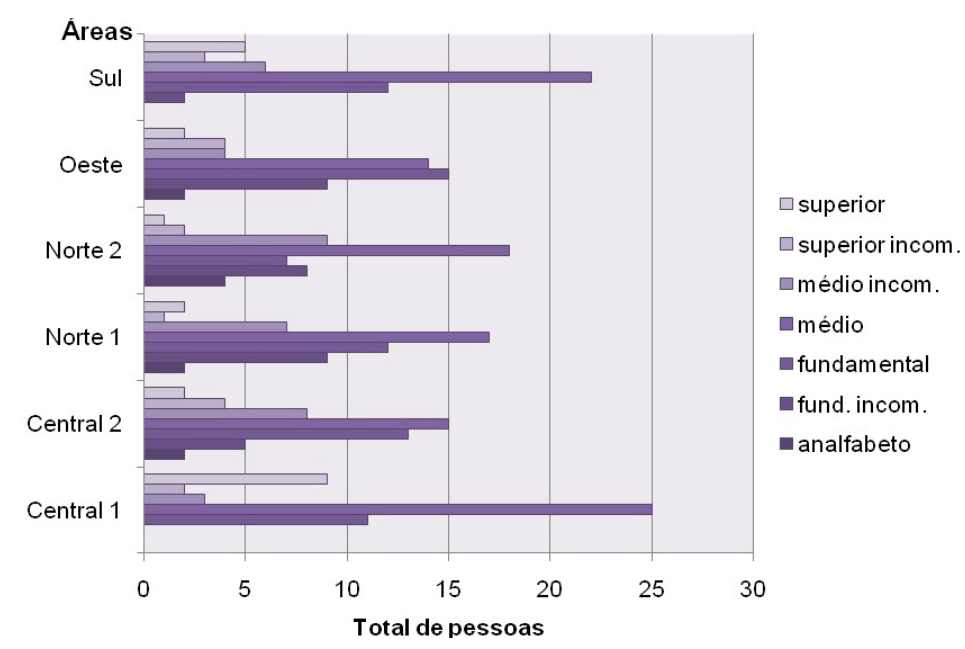

Figura 5 - Gráfico da Escolaridade dos participantes
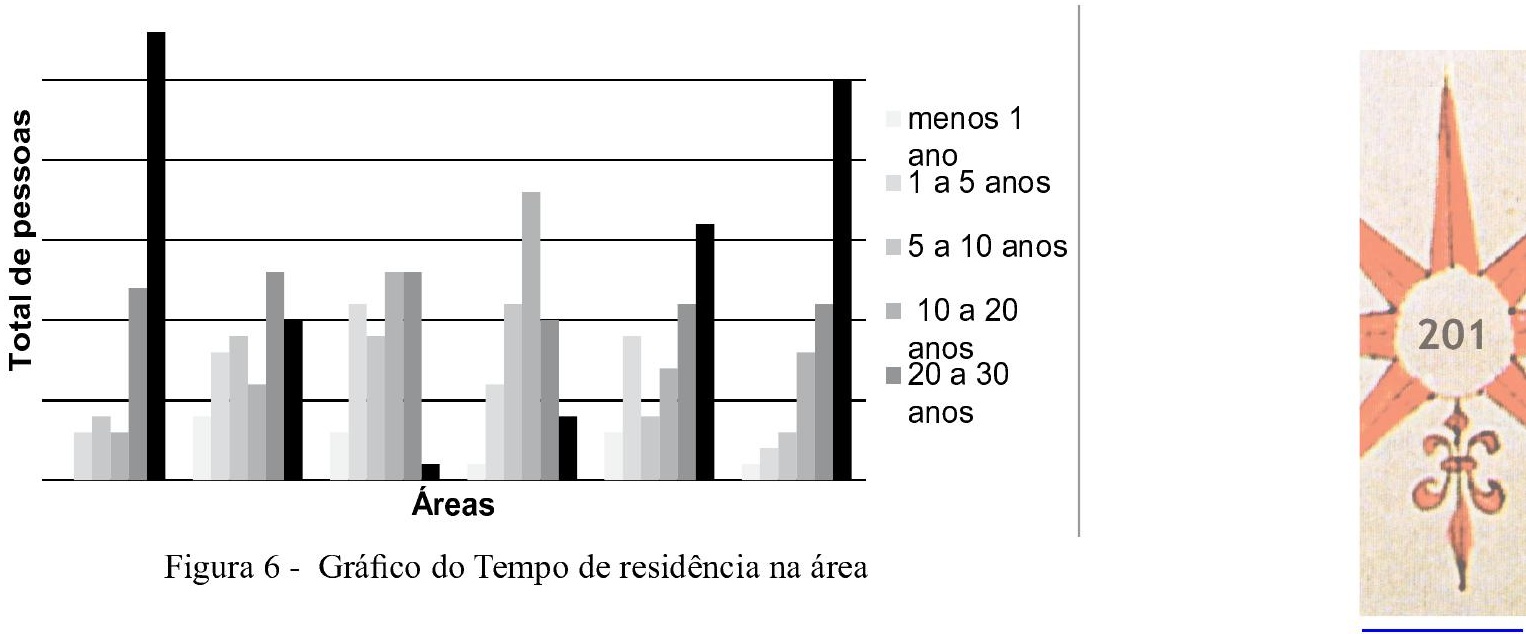

Nenhum dos entrevistados teve casos de Leptospirose na residência, no entanto, alguns dos participantes tiveram casos de dengue, com maior predomínio na região Norte 2 e Norte 1 dentre os moradores entrevistados. (figuras 7).

Dentre as categorias analisadas, primeiramente identificou-se o conhecimento das medidas de prevenção das doenças de veiculação hídrica, a estação do ano e/ou a época frequente da ocorrência dos casos.

O conhecimento é importante na perspectiva do risco, pois é "a ferramenta inicial para pensar em qualquer intervenção que possa minimizá-lo para garantir segurança às pessoas e aos lugares" (GODIM, 2007). É preciso saber o que as pessoas sabem sobre a realidade epidemiológica a que estão expostas, se possuem conhecimento pertinente para se prevenir e enfrentar o risco.

Sobre o conhecimento das medidas de prevenção, em todas as áreas, os participantes responderam que sabem as medidas de prevenção da Dengue, muitos citavam as formas de prevenção e combate ao vetor, que são divulgadas na mídia e também nas campanhas do Ministério da Saúde, como por exemplo: não deixar água parada, colocar areia nos vasos, limpar a caixa d'água e a calha, além de colocar sal nos ralos de casa. 


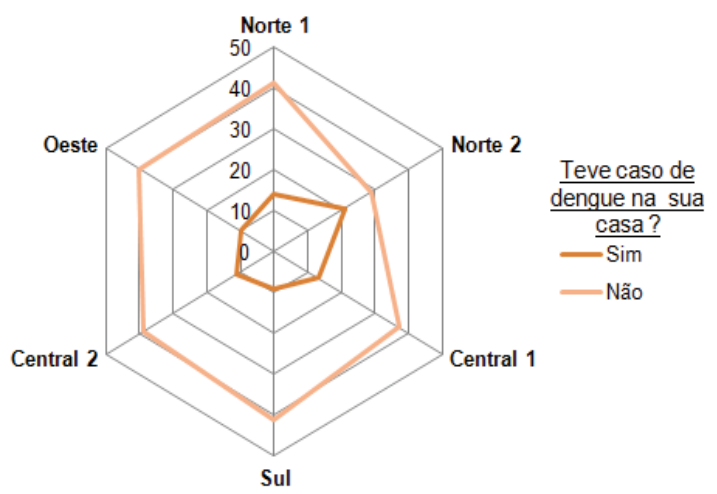

Figura 7 - Ocorrência de casos da dengue entre os participantes

Com relação à Leptospirose, a maioria dos participantes disse não saber como se prevenir, algumas pessoas que disseram saber citavam o cuidado no contato com as águas das inundações, a limpeza da casa e de terrenos baldios como formas de prevenção. A maioria dos participantes que tem este conhecimento são moradores das áreas Central 1, Central 2 e Sul, ambas apresentam pontos de inundações frequentes durante o verão. (figura 8).

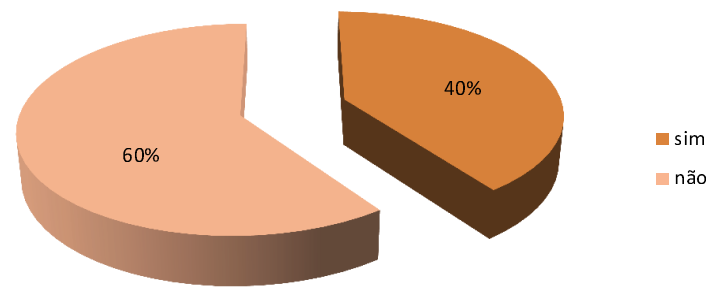

Figura 8 - Quantidade de pessoas que sabem as medidas de prevenção da Leptospirose

A mídia junto com os profissionais de saúde, ou seja, agentes de controle de vetores, são os principais responsáveis pela disseminação da informação sobre as medidas de prevenção da Dengue e da Leptospirose. (figura 9).

Ainda sobre o conhecimento do período ou estação do ano em que ocorrem os surtos das doenças, a maioria dos participantes respondeu como alternativa o período chuvoso, que foi incorporado na estação do verão, pois, a percepção da população sobre o clima muitas vezes pode divergir das reais condições habituais de cada estação, ou muitas vezes, a informação é simplificada como a estação das águas relacionada ao verão, que na linguagem popular se refere ao período chuvoso mencionado pelos entrevistados. (Figuras 10 e 11).

Outra categoria analisada foi a conduta resultante, que traz a informação da experiência sobre os fatores de risco e do comportamento, é nessa categoria que os valores positivos e negativos surgem como antônimos qualitativos, que ajudam a identificar a capacidade de geração das informações críticas dos moradores sobre o cotidiano vivenciado, a partir da satisfação, da insatisfação e do conhecimento sobre o problema. Neste contexto, forma-se o juízo informacional atuante ou indiferente perante o risco vivido.

Praticamente em todas as áreas, os participantes colocam em prática as medidas de prevenção conhecidas, exceto na área Norte 2, em que dois deles relataram que por ficarem muito tempo distantes de casa para trabalhar, quando retornam a noite, acabam não realizando todas as medidas de prevenção, como pode-se observar na figura 12 . 


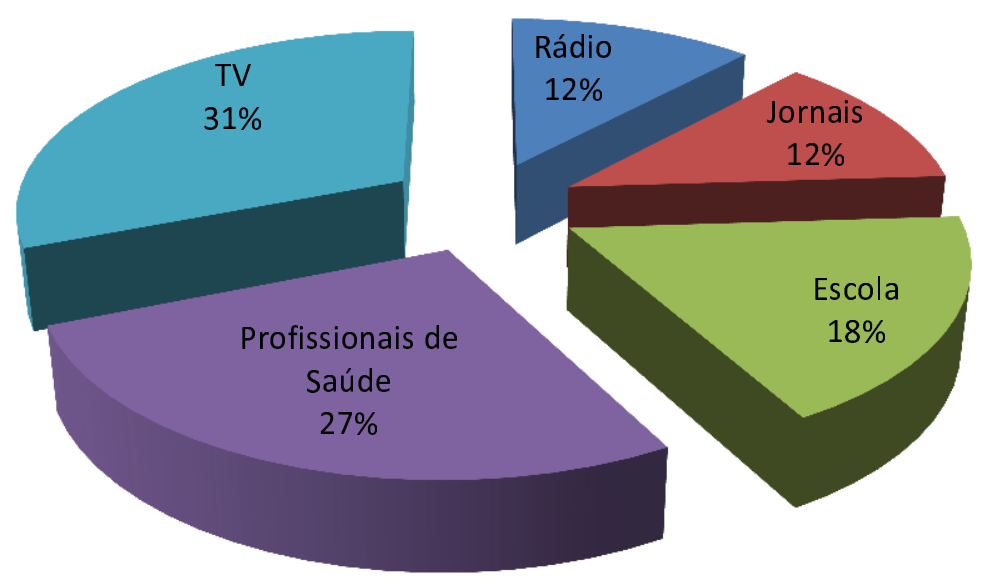

Figura 9 - Fontes de informação das medidas de prevenção

O período da prática é constante de acordo com a maioria dos participantes, conforme visto na figura 13, entretanto, em todas as áreas uma pequena parte mencionou que apenas no período do surto é que se lembra de colocar em prática as medidas de prevenção.

Além disso, muitas vezes a divulgação da informação quanto a prevenção da doença ocorre apenas no verão, com possibilidade de criadouros artificiais já terem se instalado nos domicílios, e darem origem a vetores de transmissão da dengue que podem atingir a vizinhança. Se a grande maioria dos participantes afirma colocar em prática as medidas de prevenção (Gráfico 10 e 11), por outro lado, atribuem "aos outros" o problema.

Os moradores acreditam que a falta da população colocar em prática o que sabe, ou seja, as medidas de prevenção contra a dengue, é que faz com que a doença continue a reincidir todos os anos nas áreas em que vivem. Isso ocorre, porque o comportamento cobrado da vigilância em saúde é que cada morador cuide de sua casa, mas, dependendo do tipo de relação estabelecida e do sentimento predominante entre a vizinhança, essa diretriz torna-se insuficiente para a prevenção do risco.

Muitos moradores mencionaram que essa conduta individual deveria ser mais fortalecida pela cobrança de multa das casas que não deixassem o agente do controle de vetores entrarem e também naquelas em que fossem encontrados focos do mosquito. Assim, o problema parece ser o outro, e a forma política de sensibilização da população pelo conhecimento e importância do problema, aparece sempre em segundo plano.

A satisfação de viver no ambiente é outro aspecto, relacionada a uma realidade ambiental existente têm influência sobre os riscos epidemiológicos, uma vez que, as pessoas são partes dos problemas nos quais estão contidas, e tem a possibilidade de agir de acordo com o que presenciam no seu cotidiano, "nesta perspectiva, é necessário enxergar a singularidade de cada um e a unicidade de todos". (GODIM, 2007).

Dentre as categorias mensuradas nos questionários, para avaliar a satisfação com relação ao ambiente, os moradores atribuíram uma nota de 1 a 10 para cada aspecto relacionado ao lugar vivido, com a nota 1 significando ruim e 10 ótimo.

Ressalta-se que, durante a aplicação dos questionários foram percorridos quarteirões, aplicando no máximo 2 questionários em cada, pois, concordando com Yi-Fu Tuan (1983):

A rua onde mora é parte da experiência íntima de cada um. A unidade maior, o bairro, é um conceito. O sentimento que se tem pela esquina da rua local não se expande automaticamente com o passar do tempo até atingir todo o bairro. O conceito depende da experiência, porém não é conseqüência inevitável da experiência (TUAN, 1983, p. 189) 


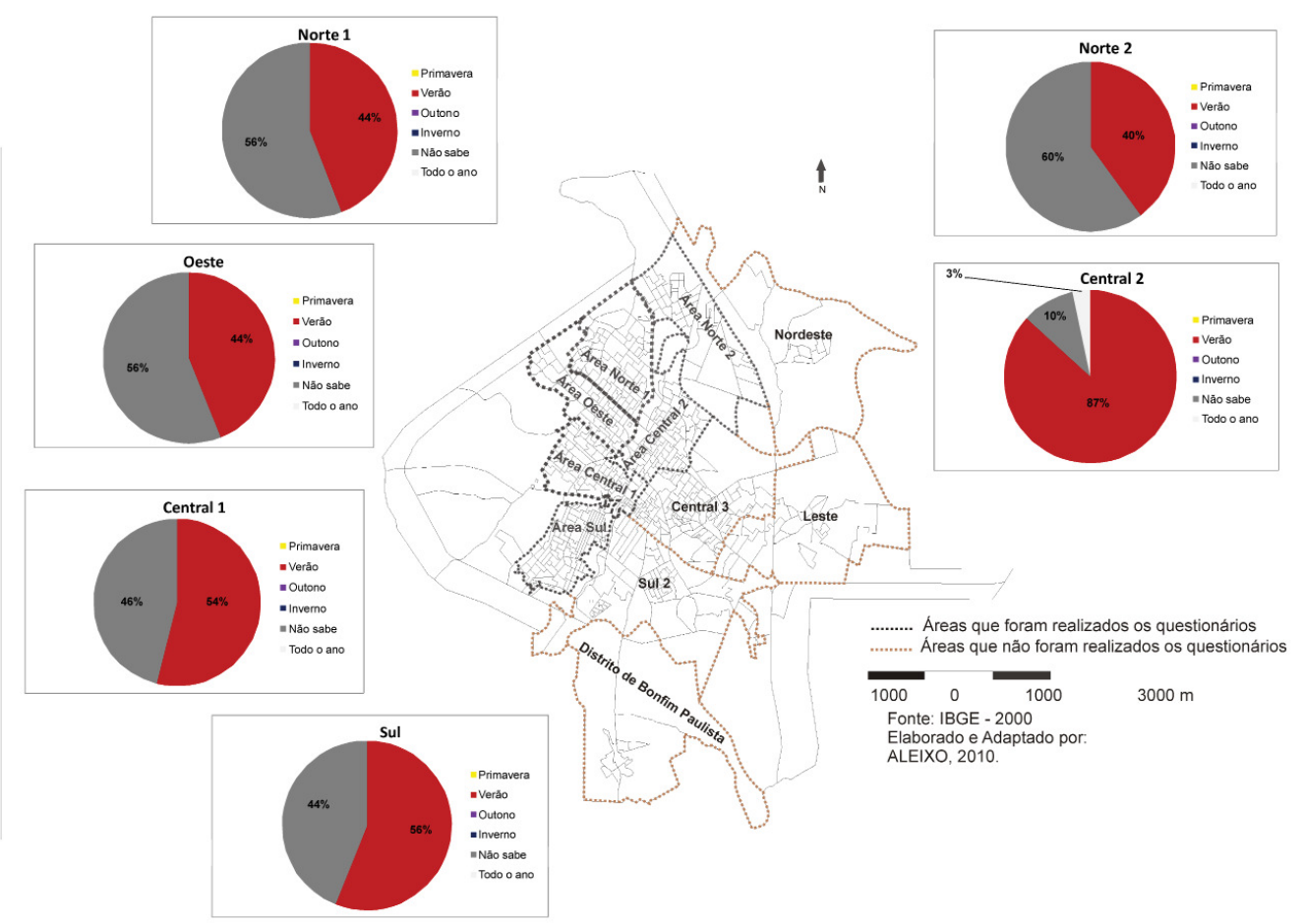

Figura 10 - Período do ano em que ocorrem mais casos de Dengue, segundo os entrevistados

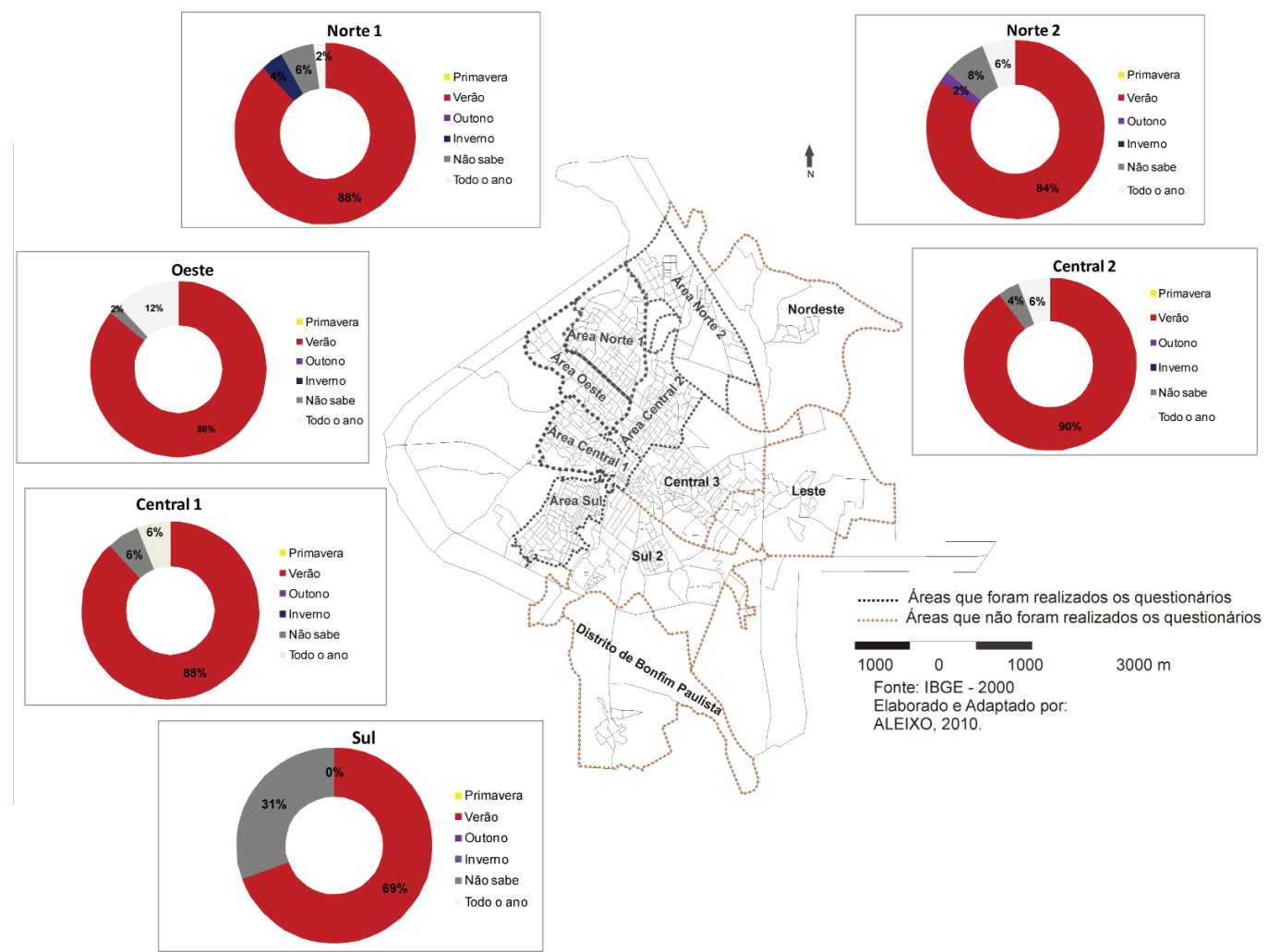

Figura 11 - Período do ano em que ocorrem mais casos de Leptospirose, segundo os entrevistados. 


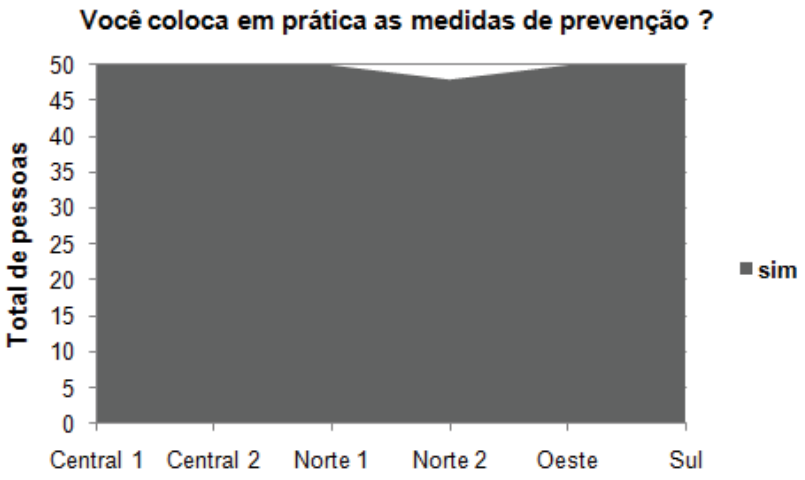

Figura 12 - Conduta dos participantes sobre as medidas de prevenção

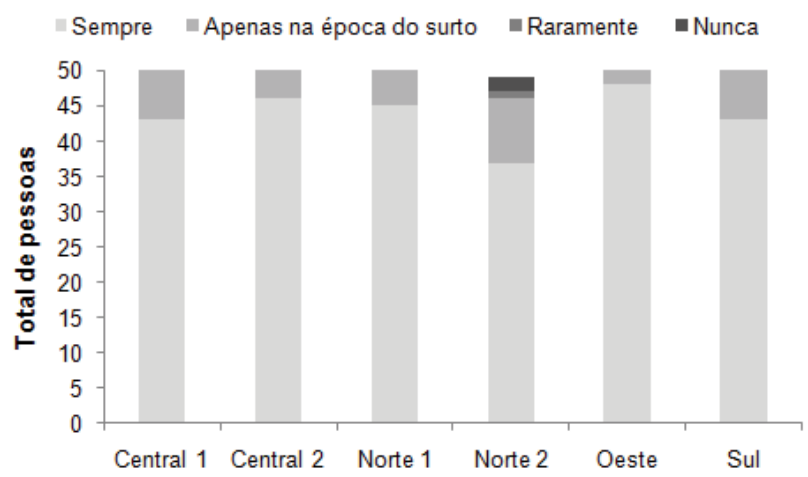

Figura 13 - Período em que os participantes colocam em prática as medidas de prevenção

Dentre os aspectos questionados, a limpeza das ruas e terrenos baldios tiveram notas muito baixas na área Oeste, que também obteve as menores notas pela limpeza de canais, bueiros e córregos, lembrando que na área, ocorrem episódios de inundações frequentes durante o verão (figuras 14 e 15). O recolhimento de lixo domiciliar obteve notas altas em todas as áreas, demonstrando que este não representa problema para o desenvolvimento de criadouros potenciais. (figura 16)
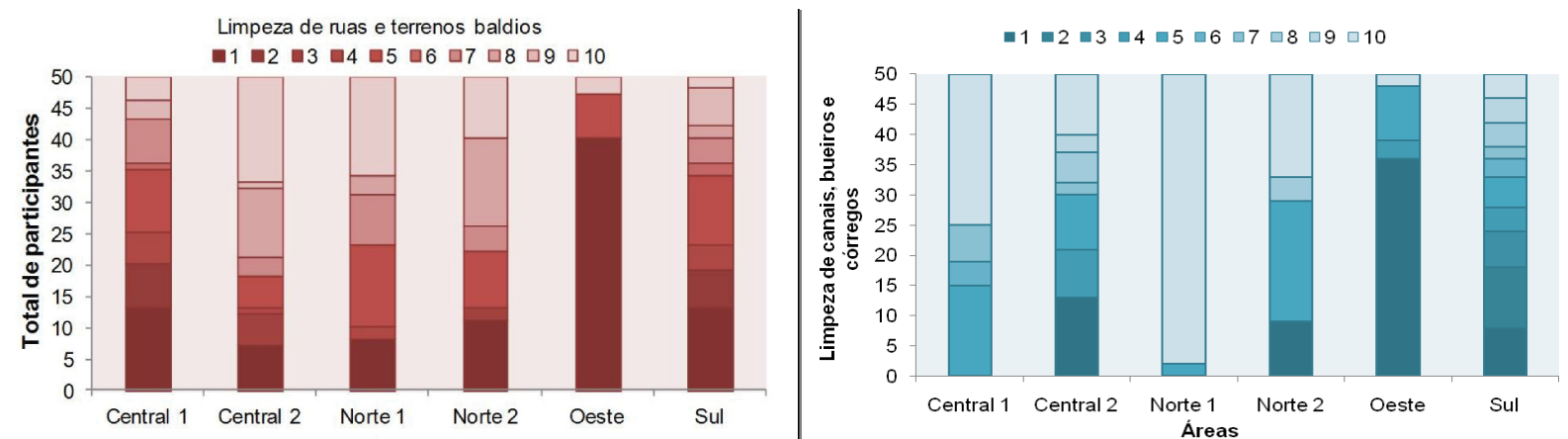

Figura 14 e 15 - Limpeza de ruas e terrenos nas áreas (à esquerda) e Limpeza de canais, bueiros e córregos nas áreas (à direita)

Com relação a arborização urbana, ocorreram diferenças significativas nas notas entre as áreas, a avaliação negativa deste aspecto predominou nas áreas Sul e Oeste.

Os participantes mencionaram a falta de vegetação arbórea nas ruas, a falta de praças pelo bairro, e também a falta de manutenção das praças que impossibilitavam a sua função de lazer e convívio social. (figura 17)

Entretanto, as áreas Central 1 e 2 obtiveram posições medianas entre a menor nota e a maior.

Os serviços de saúde receberam notas baixas dos participantes das áreas Sul e Oeste, que reclamaram da demora no atendimento e de conflitos com os profissionais da saúde na Unidade Básica de Saúde (UBS) do local. 

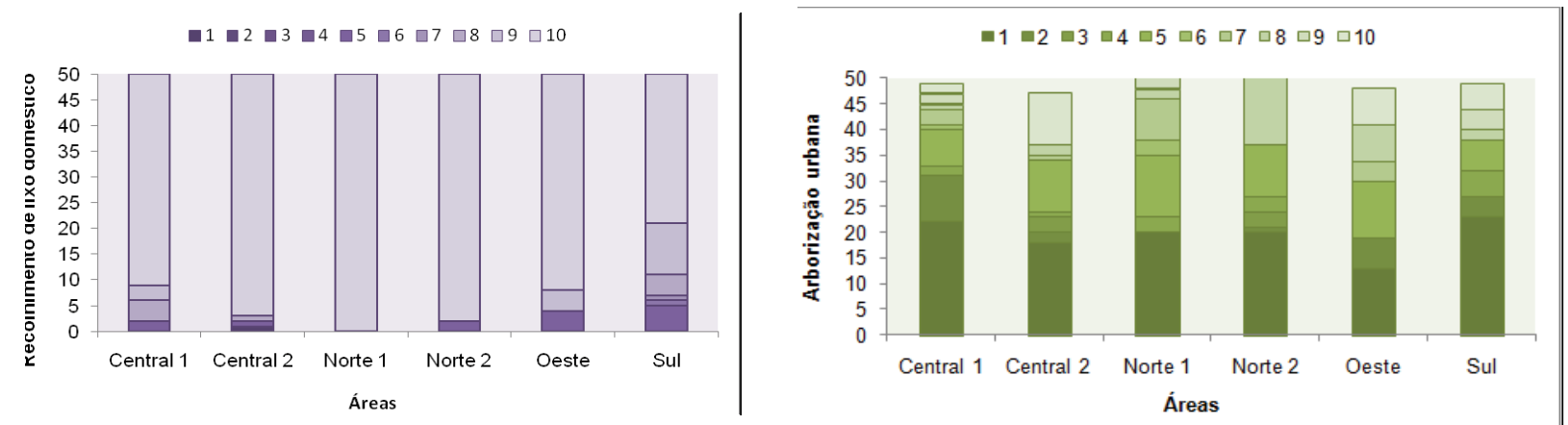

Figura 16 e 17 - Recolhimento de lixo domiciliar nas áreas (à esquerda) e Arborização urbana nas áreas (à direita)

Nas áreas Norte 2 e Norte 1, os participantes que avaliaram com nota baixa, reclamaram da alta demanda de moradores dos bairros que eram divididos em diferentes UBS para atendimento, isso ocasionava demora na consulta. As áreas Central 1 e 2, foram em maioria bem avaliadas neste aspecto. (figura 18).

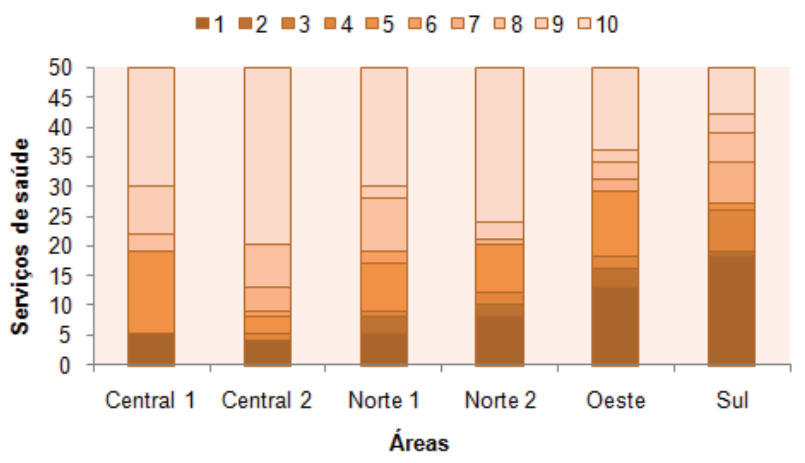

Figura 18 - Atendimento no serviço de saúde nas áreas

A percepção sobre o sentimento dos moradores relacionado ao risco vivenciado, foi identificada por uma questão sobre como a pessoa se sente vivendo num ambiente que tem muitos surtos de dengue ou leptospirose.

Os sentimentos envolvidos no risco vivenciado interferem de forma positiva ou negativa nas decisões, e faz com que o pensar em conjunto e a troca de informações na escala da vizinhança seja fácil ou não, pois, na sociedade atual a valorização do comportamento individualista (cada um que faça sua parte) e egocentrista dificultam ainda mais esse tipo de relação.

Apenas na área Norte 2, uma pessoa respondeu que teve remorso por não colocar em prática as medidas de prevenção das doenças, também porque a maioria das pessoas ao responderem a questão sobre a conduta, disseram que colocam em prática o seu conhecimento sobre as formas de prevenção.

Como pode-se observar na figura 14, os moradores ficam preocupados em morar nas áreas que apresentam muitos casos dessas doenças, mas, a frustação também foi bem citada entre os participantes, demonstrando que muitos moradores ficam desmotivados de fazerem a sua parte na prevenção da dengue e verem que seus vizinhos, não têm a mesma conduta.

Este sentimento, pode ser extremamente prejudicial no combate ao vetor e controle da doença. O sentimento de frustação aparece nos moradores de todas as áreas, mas é predominante na área Central 1.

O medo de adquirir a patologia também foi mencionado pelos participantes de todas as áreas da cidade, com predomínio na Norte 1, ao mesmo tempo que este sentimento auxilia na prevenção pela forma arisca que as pessoas vêem o risco, pode trazer complicações psico-sociais negativas a longo prazo.

$\mathrm{Na}$ área Norte 2, a raiva, foi o sentimento predominante nos participantes. Muitos diziam, por exemplo, que tinham conversado com vizinhos sobre a falta de conduta preventiva deles no controle do vetor da dengue, mas nada mudou. 
A raiva pode se relacionar a ausência de autoridade central e a perda de controle pelas autoridades locais, gerando forte insegurança e aumento no número de agressões, além da falta de proximidade e troca de informações no viver em conjunto, possibilitando o aumento do risco de incidência. Este sentimento deve ser combatido, de forma que o diálogo e a integração da comunidade facilitem a educação em saúde.

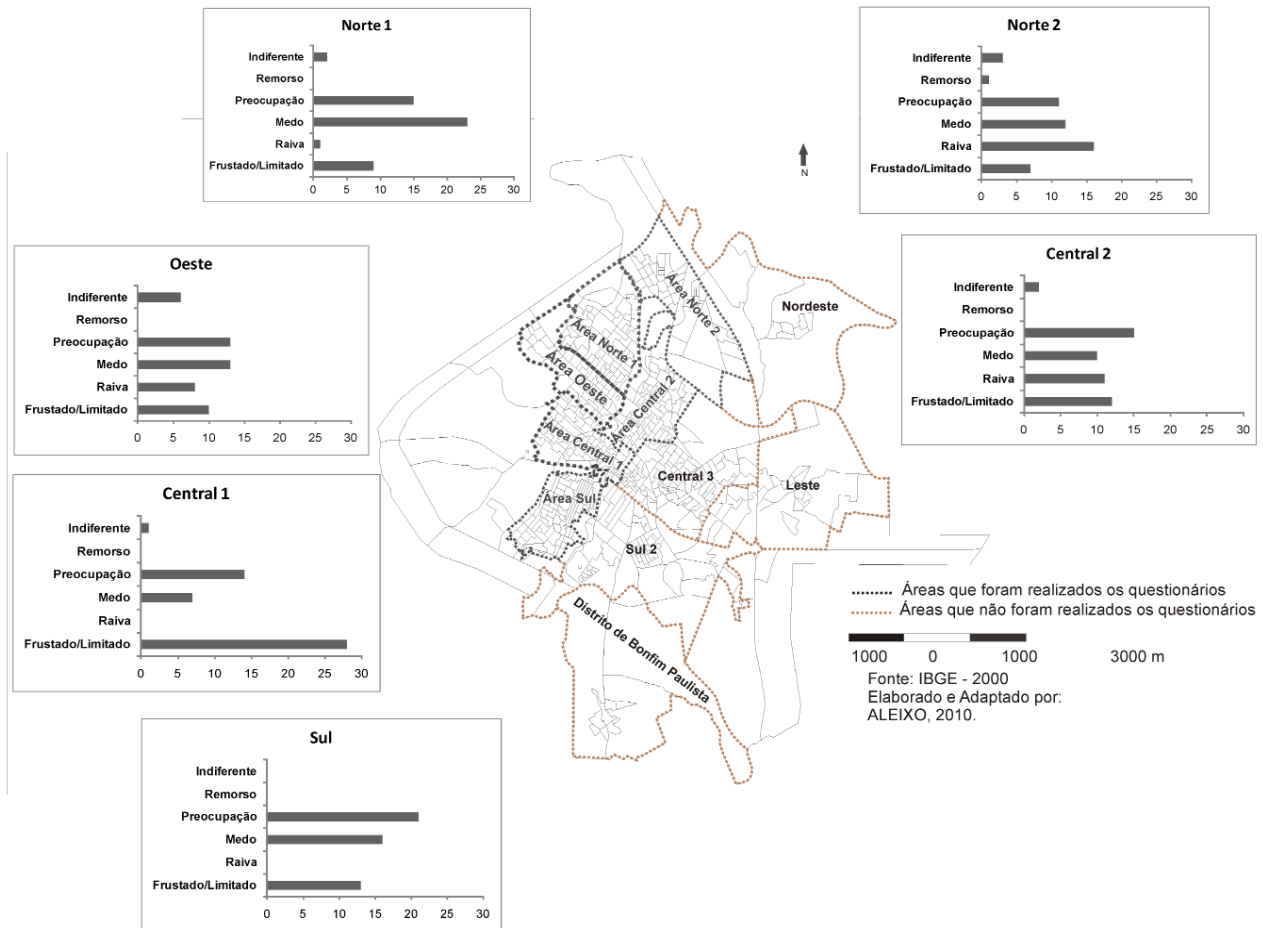

Figura 22 - Sentimento predominante da relação ambiente e saúde entre os entrevistados

\section{CONSIDERAÇÕES FINAIS}

A relação saúde e ambiente não pode mais ser tratada de forma isolada, é preciso integrar diferentes fatores: físicos, sociais, econômicos, políticos, culturais e epidemiológicos, para a redução do risco das doenças e agravos, promoção da saúde e acesso igualitário aos serviços de saúde, em uma perspectiva interdisciplinar.

A percepção dos riscos se insere nesta perspectiva, uma vez, que os determinantes objetivos e subjetivos do processo saúde-doença, precisam ser identificados para a eficácia das políticas públicas de saúde.

Dentre as doenças de veiculação hídrica pesquisadas, os moradores demonstraram saber as medidas de prevenção e a época do ano em que é mais frequente a ocorrência da dengue. No entanto, pelos poucos casos e por não possuir uma ampla campanha de combate a doença, os moradores em maioria, desconhece a principal época de ocorrência da Leptospirose e as medidas de prevenção da doença.

Com relação à reincidência de casos dessas doenças nas áreas, os moradores acreditam que se deve a parte da população que não coloca em prática as medidas que sabem sobre a prevenção e combate ao vetor.

Isso gera os mais variados sentimentos nas pessoas, principalmente a preocupação, o medo e a raiva, que traduzem uma sensação de forte insegurança com o ambiente vivido, a falta de proximidade e troca de informações no convívio social, que poderiam auxiliar na prevenção das doenças. Além da frustração, que desmotiva a conduta preventiva nas pessoas.

Por isso, os comportamentos de risco identificados, podem propiciar que medidas de planejamento e politicas públicas sejam formuladas ou reformuladas no ambiente urbano, contribuindo no fortalecimento das relações sociais nas comunidades, para construção de um viver saúdável na cidade. 


\section{REFERÊNCIA BIBLIOGRÁFICA}

BARCELlOS, C. Elos entre a Geografia e Epidemiologia. Cadernos de Saúde Pública, v. 16, n.3, 2000. BRASIL, Ministério da Saúde, Secretaria de Vigilância em Saúde. Guia de vigilância epidemiológica. Ministério da Saúde, Brasília, Dengue: p. 231-253, 2001.

BECK, Ulrich. Risk society: towards a new modernity. (trad. Mark Ritter) London: Sage, 1992.

CASTIEL, L.D. Lidando com o risco na era midiática. In: M C MINAYO; A. C. MIRANDA. (Org.). Saúde e ambiente sustentável: estreitando nós. Rio de Janeiro: ABRASCO/FIOCRUZ, 2002, p. 113-133.

CIAMB. Seminário Internacional: Riscos, saúde e meio ambiente (2009). Disponível em: http://ciamb.prppg. ufg.br/pages/19298. Acesso: 10/1/2010.

CONFALONIERI, U. E. C. A crise ambiental e suas repercussões na saúde humana. In: M C MINAYO; A C MIRANDA. (Org.). Saúde e ambiente sustentável. Rio de Janeiro: ABRASCO/FIOCRUZ, 2002, p. 51-54. DEL RIO, V; OLIVEIRA, L.(org). Percepção Ambiental. 2.ed. São Paulo: Studio Nobel, 1999 DONALISIO, MRD. O Dengue no Espaço Habitado. São Paulo: Hucitec, 1999.

GODIM, G.M.M. Do conceito de risco ao da precaução: entre determinismos e incertezas. In.: Fonseca, F. A; Corbo, A. D. (orgs.) O território e o processo saúde-doença. Rio de Janeiro: Fiocruz, 2007.

HOGAN, D. J e MARANDOLA JR, E. Natural hazards: os estudos geográficos dos riscos e perigos. Ambiente e sociedade, vol. 7, n. 2, jul./ dez 2004. p. 95-109.

HOGAN, D. J. e MARANDOLA JR, E. Towards an interdisciplinary conceptualisation of vulnerability. Population, Space and Place, n. 11, 2005. p. 455-471.

KOURY, M.C.; SILVA, V. Epidemiologia e Controle da Leptospirose Humana nas Regionais do município de Belo Horizonte. Relatório do projeto desenvolvido no Centro Univ. Metodista, Belo Horizonte, 2006.

LIEBER, R.R.; LIEBER, N.S.R. O conceito de risco: Janus reinventado. In: M C MINAYO; A. C. MIRANDA. (Org.). Saúde e ambiente sustentável. Rio de Janeiro: ABRASCO/FIOCRUZ, 2002, p. 69-112. MENDONÇA, F. Geografia socioambiental. In: Elementos de epistemologia da geografia contemporânea. Curitiba: UFPR, 2002.

NOSSA, P. Linhas de investigação contemporâneas na Geografia da saúde e a noção holística de saúde. In: A Geografia e o contexto dos problemas de saúde. Rio de Janeiro: ABRASCO, 2008.

OLIVEIRA, L. Ainda sobre percepção, cognição e representação em Geografia. In: Elementos da Geografia Contemporânea. Ed. UFPR: Curitiba, 2002

PONTES, R.J.S; RUFINNO-NETO, A. Dengue em localidade urbana da Região Sudeste do Brasil: Aspectos Epidemiológicos. Revista de Saúde Pública, São Paulo, 28 (3): 218 - 27, 1994.

ROUQUAYROL, M. Z. Epidemiologia \& Saúde. 4ª Ed. Rio de Janeiro: Medsi, 1994.

SUCEN. Dengue: Aspectos epidemiológicos. Disponível em: $<$ http://www.sucen.org.br/crmonline/jornalcrm/175/opiniao_0302.htm>. Acesso em 24 set de 2009.

SILVERMANN D. Interviews. In: Qualitative Research theory, method and practice. London: Sage publications, p. 08-217, 1997.

SPINK, M.J. Trópicos do discurso sobre risco: risco-aventura como metáfora na modernidade tardia. Cad. Saúde Pública vol.17 no.6 Rio de Janeiro Nov./Dec. 2001

TUAN, Yi-fu. Espaço e lugar: a perspectiva da experiência. São Paulo: DIFEL, 1983.

VEYRET, I. Os riscos: O homem como agressor e vítima do meio ambiente. São Paulo: Ed. Contexto, 2007. ZANIRATO, S. H. et al. Sentidos do risco: interpretações teóricas. Biblio 3W, Revista Bibliográfica de Geografía y Ciencias Sociales, Universidad de Barcelona, Vol. XIII, nº 785, 25 de mayo de 2008.

WHO - World Health Organization - Emerging issues in water and infectious disease, 2003.

WOLFGANG, L.C. A sociedade do risco. Até uma nova realidade. (Resenha). Recanto das letras, 2009.

Trabalho enviado em maio de 2011 Trabalho aceito em junho de 2011 